\title{
Strengthening comprehensive sexuality education in the curriculum for the early grades
}

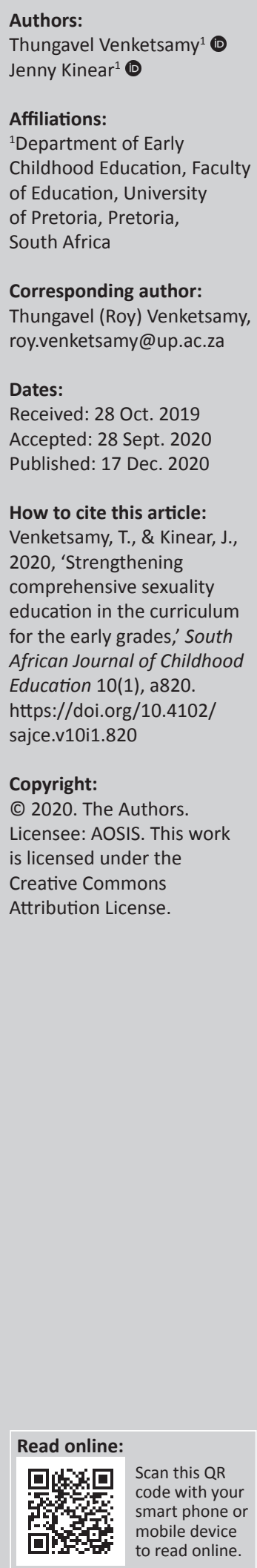

Background: The continuing high rate of child abuse and sexual violence has highlighted the need for a focused intervention in the form of educating young learners on sexual risks and protection against harmful behaviours and making them aware of their right to be protected.

Aim: The aim of this article is to strengthen the comprehensive sexuality education (CSE) curriculum for the early grades and to gain an understanding of teachers' knowledge of CSE and how it is linked to the Curriculum and Assessment Policy Statement (CAPS): Life Skills.

Setting: This study was conducted at two schools in different districts in the Gauteng Province, in environments where rich data could be solicited from the participants regarding their knowledge of how to strengthen CSE in the curriculum.

Methods: A qualitative case study was conducted that included eight Foundation Phase teachers and two subject advisors. One focus group interview was held with teachers and subject advisors. The analysis of documents containing teachers' and subject advisors' notes was examined through the lens of the Behaviour-Determinant-Intervention (BDI) Logic Model.

Results: The data gathered showed the following significant gaps in CAPS: Life Skills CAPS need to be addressed and aligned to the International Technical Guidelines on Sexuality Education (ITGSE), and teachers need to be adequately trained in the content and teaching methodologies of CSE in the early grades.

Conclusion: The CAPS curriculum must be aligned to the ITGSE. Teachers need to be trained; detailed scripted lesson plans should be made available to all early-grade teachers and appropriate resources should be provided to support teaching and learning to strengthen the CSE implementation.

Keywords: comprehensive sexuality education; early grades; curriculum; sexuality education; behaviour-determinant-intervention logic model.

\section{Introduction}

Widespread sexual violence involving both girls and boys has become a serious concern worldwide (Artz et al. 2018). The high rates of child abuse and sexual violence have highlighted the need for a focused intervention to educate young learners on sexual risks and protection against harmful behaviour and to promote awareness of their right to be protected (Kirby 2011b; Mathews \& Collin-Vezina 2019). In one primary school in Gauteng, Pijoos (2017) reported 54 cases of sexual assaults on learners. He also provided evidence of a scholar patrol officer who had sexually violated 87 young learners from Soweto in Gauteng Province.

This dangerous sexual behaviour is not reported in South African schools only; Express News in the United Kingdom reported that children aged below 12 years were involved in sexting and highlighted challenges experienced with the responses of parents when confronted with their children's sexual behaviour. Ashcraft and Murray (2017) believe that parents and teachers have a significant influence on children's decisions about sex, and according to Venketsamy (2018), both teachers and parents are anxious about young children learning sexuality education (SE) content at school.

This article aims to strengthen the comprehensive sexuality education (CSE) curriculum for the early grades (Grade R-3, children between the ages of 6 and 8 years) and to gain an understanding of teachers' knowledge and understanding of CSE and its links to the Curriculum and Assessment Policy Statement (CAPS): Life Skills. 
In response to the alarming statistics of sexual abuse and activities amongst young learners, the South African Department of Basic Education (DBE), in collaboration with the Departments of Health (DoH) and Social Development (DSD), developed the Integrated Strategy on human immunodeficiency virus (HIV), sexually transmitted infections (STIs) and tuberculosis (TB) 2012-2016 (DBE 2017) and the Draft Policy on HIV, STIs and TB (DBE 2011b). The key components of the strategy are to increase HIV, STIs and TB knowledge and skills amongst learners, educators and officials; decrease risky sexual behaviour amongst learners, educators and officials and decrease barriers to retention in schools, in particular, for vulnerable learners. Strengthening teaching and learning of CSE in the curriculum includes more than identifying the subject content gaps but requires exploring what will increase teacher competence and comfort levels to teach sexuality effectively in the classroom.

\section{The difference between comprehensive sexuality education and sexuality education}

Comprehensive sexuality education is described as a curriculum-based process of teaching and learning that includes a focus on the emotional, cognitive, physical and social dimensions or aspects of sexuality. Whilst the teaching includes the knowledge that children and young people need to know, it also recognises the need for the development of skills, values and attitudes. These skills, values and attitudes will empower them to understand and protect their rights, guide their choices and help them understand how their choices might affect their well-being, make them realise the importance of their health and dignity and develop respectful social and sexual relationships (UNESCO 2015a).

Comprehensive sexuality education aims to provide students with the knowledge, attitudes, skills and values required to make appropriate healthy choices about their sexual lives (Kirby 2011b). According to the UNFPA (2015), CSE has been defined as a 'rights-based and gender-focused approach to sexuality education, whether in school or out of school' and embraces a holistic vision of sexuality, sexual behaviour and personal development (DBE 2017).

The rights-based approach, according to Berglas, Constantine and Ozer (2014), encompasses elements that young people have sexual rights; that the curricula content should include issues such as gender norms, sexual orientation, sexual expressions, individual rights and responsibilities and a participatory teaching strategy that engages young people in critical thinking about their sexuality and sexual choices. In South Africa, these rights are articulated in the Constitution of 1996 whereby 'every child has the right to be protected from harm, be protected from abuse and that every child receives a quality education to ensure his or her well-being'. The South African Constitution (Act 108 of 1996) sets out the social goals for social justice, human rights, inclusivity and a healthy environment, which is mirrored in the Manifesto for Values, Education and Democracy (DBE 2002:1). The manifesto provide 'strategies for instilling democratic values in young South Africans and nurturing a culture of sexual and social responsibility' (DBE 2002:8). Through strengthening of the curriculum in the early grades, young people will be given the opportunity of receiving age- and gradeappropriate CSE that will help them to make appropriate decisions in their adolescence (Kirby 2011b).

Sexuality education, however, is a lifelong process of acquiring information and forming beliefs, values and attitudes. It aims to contribute to a change in behaviour, including the reduction of unprotected and unwanted sex, as well as of harmful behaviour, including sexual offences such as assault and abuse (Family Planning, no date). UNESCO (2009:16) posits that SE is rights-based, culturally influenced, age-appropriate and scientific, and that information should be curriculum-based.

Sexuality education includes a range of topics that are adapted to the age and developmental level of the child. Children aged between 4 and 6 years learn about topics such as friendship, emotions, different body parts and different kinds of touching, which are also relevant for older children and adolescents but are then taught at a different level (UNESCO 2009). In contrast to CSE, international countries such as the United States have opted for 'abstinence-based education' (Ott \& Santelli 2007). Abstinence-only sex education is a form of sex education that teaches not having sex outside of marriage. It often excludes other types of sexual and reproductive health education; Abstinenceonly curricula have been found to contain scientifically inaccurate information, distorting data on topics such as condom efficacy and promote gender stereotypes. Kirby (2011b) states that broad public support exists for CSE, with abstinence as a key component of the education.

\section{The importance of comprehensive sexuality education in the early grades}

In the early grades (Grades $\mathrm{R}$ to 3 ), children talk about personal topics mainly with family members and subsequently in the extended environment. Honest discussions about sex, sexuality, body image and relationships play an important role in the young child's sex education. Kurtuncu et al. (2015) state that this is a critical period in young learners' lives when they are learning and their personalities are being formed. They need guidance from a knowledgeable source about the above-mentioned issues.

Guder and Alabay (2018) agree with Walker and Milton (2006) that teachers and parents must be prepared to answer learners' questions about sex. It is never too early to talk about this topic. Talking to young learners about their bodies, sex and sexuality can help them to understand that sex and sexuality are normal, healthy aspects of life. Young children need to know that they should not be scared or embarrassed to ask for information on their bodies, sex and sexuality. Such open conversations amongst teachers, parents and learners help to develop trusting relationships and can prevent child 
sexual abuse or the exposure of young learners to inappropriate sexual advances (Breuner \& Mattson 2016).

Educating young children about child abuse should not be seen as teaching them about other dimensions of human sexuality. Robinson and Davies (2017) agree that there is a need for building strong, respectful relationships and ensuring sexuality literacy early in life. These are foundations for the understanding of children's sexual citizenship and their health and well-being. According to Weaver, Smith and Kippax (2005), most young people learn about sex and sexual health from school-based SE programmes. It is important that these programmes be incorporated into the curriculum. There is a need for a more balanced approach to the introduction of sex education in elementary schools. Children in Grades R to 3 ask simple and direct questions. However, older children's questions are more urgent and indicate a need for a comprehensive family-life education programme (Brick 1985).

\section{Early-grade curriculum and comprehensive sexuality education}

The curriculum for the early grades guides teachers by establishing certain achievable goals regarding the knowledge, skills and dispositions (attitudes) learners should acquire and develop. It is recommended that a good curriculum should be a written document that is used when planning experiences for children. Considering the high rate of child sexual abuse, a detailed CSE curriculum is essential.

The UNESCO (2015b) report indicates that there has been an increased focus on strengthening curricula in several countries. Reviews of curricula indicate that increased attention is required to promote the development of key competencies and to examine the extent to which gender norms, religion and culture influence learners' attitudes and behaviour. Although CSE content must be adapted to reflect local contexts, certain core topics must be included to maintain quality and meet international standards.

Effective teaching of CSE content is dependent on appropriate responses to the specific contexts and needs of young people (UNESCO 2015b). This adaptation of the content is fundamental to culturally relevant programming and includes understanding the messages that cultures convey regarding gender, sex and sexuality. The content of CSE should be adapted according to the age and grade level of the learners. The content of the CSE curriculum for young learners between the ages of 5 and 8 years focuses mainly on 'relationships, friendship, love, tolerance, inclusion respect, tolerance, gender' (UNESCO 2009). As is the case with all curricula, CSE must be in line with national laws and policies.

The DBE has recognised that in the Foundation Phase, purposeful and content-specific focus on CSE is required in the Life Skills programme. To achieve the health goal of changing or improving risky behaviour in later grades, necessary SE content should be included as early as in Grades
R to 3 (DBE 2017). The DBE (2017:17) explicitly states that 'the provision of quality CSE has been identified as a gamechanger to accelerating prevention'.

According to the DBE (2011a), the CAPS for Foundation Phase indicates that Life Skills is where a CSE approach can be followed to introduce relevant, age- and gradeappropriate knowledge and concepts in the early grades. This provides an opportunity to increase learners' knowledge base and their ability to make good decisions related to healthy sexuality and reproductive health as early as in Grades R to 3.

In the Foundation Phase (Grades R to 3), CSE is taught in the CAPS subject Life Skills under the topic Personal and Social Well-being (DBE 2011a). Content and concepts related to CSE do not exist on their own. They are integrated into the topics in the Life Skills curriculum. Kirby (2011b) states that the opportunities offered by the CAPS for the inclusion of CSE are specific and limited. Determining how CSE could be incorporated into the CAPS relies on an analysis of the CAPS, the identification of where CSE content could be included and what teachers will need to support the teaching of CSE.

In his research, Kirby (2011b) identified content gaps in SE in the South African curriculum that prevents adequate and appropriate implementation of SE as outlined in the International Technical Guidance on Sexuality Education (ITGSE): An evidence-informed approach for schools, teachers and health educators. He determined that the South African CAPS specifies broad topics to be covered during each grade, term and week and the number of hours allowed for different topics but contains minimal information on CSE. Identifying gaps in content and then finding ways in which those gaps might be filled have further implications for teacher development. Table 1 indicates the gaps identified in the Foundation Phase curriculum.

Kirby (2011b) examined the topics and sub-topics in Life Skills in the CAPS and mapped them out against the characteristics for effective programmes in the ITGSE Vol II (Ages 5-8). The topics and sub-topics were not deconstructed into concepts to be taught in units in a daily programme. The following emerged from the comparison:

Table 1 shows where the alignment of SE content with CAPS is evident, and where there are gaps in SE content (blank spaces) taught in the Foundation Phase.

If appropriate content is taught in the Foundation Phase, learners are exposed to relevant and age-appropriate content that focuses on good decision-making and good values and attitudes that will support decisions about their sexual and reproductive health later in their lives (Kirby 2011b:31). Francis (2011) (in Beyers 2013) states that teaching learners about sex and sexuality enables them not only to avoid negative outcomes but also to establish healthy attitudes towards sexuality. 
TABLE 1: A comparison between International Technical Guidelines on Sexuality Education Volume II (ages 5-8) and the Curriculum and Assessment Policy Statement (Grades R-3) regarding topics recommended to be covered.

Recommended by ITGSE, Volume II: Ages 5-8 Included in CAPS: Grades R-3

Families and marriage Family, for example, who belongs,

Friendship, love and relationships what we do and celebrate

Tolerance, acceptance and respect in Qualities of a good friend

relationships

Manners, for example, being kind and showing respect

Basic values

Commitments

Peer pressure

Decision-making

Types of communication, for example, communication, 'yes' and 'no'

Help and support

Gender

Children's rights and responsibilities

\section{Human rights}

Recognition of differences between male and female bodies (without spelling them out), changes during puberty

Basic reproduction

\section{Body image}

Body rights and privacy, sexual abuse

Keeping one's body safe, 'yes' and 'no' feelings, safe and unsafe situations, how to say no to abuse

Expressions of love, sexual activity and maturity

Basic rights and responsibilities of parenting

Disease

Rights and needs of people living with HIV

Source: Kirby, D., 2011a, A way forward: Recommendations to the South African DBE to design and implement effective HIV Education Curriculum that reduces Sexual Risk for HIV Department of Basic Education, Government Printers, Pretoria

CAPS, Curriculum and Assessment Policy Statement; ITGSE, International Technical Guidelines on Sexuality Education; HIV, human immunodeficiency virus.

\section{Theoretical framework}

For this study, the theoretical framework used is the BehaviourDeterminant-Intervention (BDI) Logic Model. The BDI model is a useful tool for designing, strengthening and evaluating programmes. Kirby (2011b) postulates that once a health goal has been identified, there is a need to determine the protective and risk factors that may affect the achievement of the health goal. Based on this, an intervention can be described for facilitating or mitigating against those factors that will influence the achievement of the desired health goal.

In the DBE (2011b) policy context, the health goal is focused on changing sexual behaviour by providing age- and gradeappropriate knowledge, skills and values on SE to Foundation Phase learners.

The BDI model is diagrammatically represented as follows:

The BDI model is built on social learning theory, which is based on the belief that 'human behaviour is determined by a three-way relationship between cognitive factors, environmental influences, and behaviour' (Kirby 2011b).

\section{Research design and method}

To elicit participants' views on strengthening CSE in the curriculum for the early grades, the researcher applied a

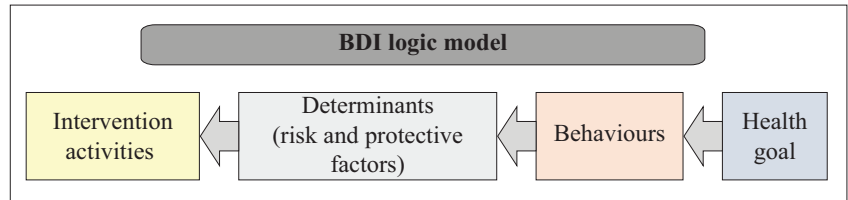

Source: Kirby, D., 2004, BDI Logic Model: A useful tool for designing, strengthening and evaluating programs to reduce adolescent sexual risk-taking, pregnancy, HIV and other STDs, ETR Associates, California. http://recapp.etr.org/recapp/documents/ bdilogicmodel20030924.pdf

$\mathrm{BDI}$, Behaviour-Determinant-Intervention.

FIGURE 1: The Behaviour-Determinant-Intervention logic model. BDI, BehaviourDeterminant-Intervention.

qualitative research approach located within the interpretivist paradigm (Yin 2018). This method offers an opportunity to explore and make meaning from participants' experiences, intentions, beliefs, values and motives for doing what they do (eds. Denzin \& Lincoln 2011). Purposive sampling was used. The participants included eight teachers (T) and two Foundation Phase subject advisors (SA) in two districts in Gauteng.

During this research, data was collected by way of in-depth focus group interviews. Structured questions were asked to elicit biographical data about the participants, whilst unstructured questions served to explore their views on strengthening CSE in the curriculum. The participants responded to the following questions: (1) how can CSE be strengthened in the Life Skills curriculum in the Foundation Phase, (2) what are the links of CSE to the Foundation Phase Life Skills CAPS? and (3) what are the factors that limit the inclusion of CSE in the early grades?

Data analysis was inductive and was based largely on information obtained from audio recordings made during individual and focus group interviews (Bloor et al. 2002). The data was analysed by using the thematic approach (Guest, MacQueen \& Namey 2012; Creswell 2009; Boyatzis 1998). The researcher compared multiple data sources in search of common themes (Mncube \& Dube 2019; Creswell 2009). To meet the requirements of the ethical code of conduct, informed consent was obtained from the participants, their anonymity, confidentiality and privacy were guaranteed, and betrayal and deception were avoided.

\section{Presentation and discussion of findings}

\section{Research findings and discussion}

The strengthening of the CSE curriculum in the early grades was categorised into three broad themes, namely, the teacher's knowledge of the policy context for CSE; the teacher's knowledge of CSE and links with Life Skills CAPS and factors that limit the inclusion of CSE in the early grades.

Verbatim quotes are used as evidence in the results.

This following section presents findings that emanated from the participants' responses regarding the strengthening of the CSE curriculum in the early grades. 


\section{Teacher knowledge of the policy context for comprehensive sexuality education}

This theme addresses what teachers know and understand about the policy context relating to the inclusion and support of CSE. The policies relevant to this study are the DBE Policy for HIV, STIs and TB (2017-2022); Integrated Strategy for HIV, STIs and TB (2012 to 2016) and the CAPS: Life Skills. These policies focus on the health goals and types of behaviour that are targeted to educate learners to improve their chances of healthy sexual and reproductive lives later in their adolescence. The nature of the subject knowledge and content that is taught in the early grades will influence learners' behaviour and the decisions they make in their lives. Teachers have to be familiar with the subject content for Life Skills and should be able to understand the linkages mapped with content from the ITGSE relevant to each grade and to teach accordingly. George et al. (2019) agree that teachers' levels of knowledge regarding the themes and lesson content are important factors in shaping their competence for lesson delivery.

The International Technical Guidance on Sexuality Education (UNESCO 2009) proposes an age-appropriate set of topics and learning objectives that constitute a CSE programme for ages 5 to $18+$. Curriculum and Assessment Policy Statement structures the content for appropriate grades based on the age group of learners, as determined by national policy, to include learners between the ages of 5 and 9 years in the Foundation Phase.

\section{Teachers' understanding of the policy context}

To establish how familiar the participants were with the policy context, they were asked which policies they thought were related to CSE. All the participants could name Life Skills CAPS and the Annual Teaching Plan as the policies most relevant to their teaching in the classroom. When a list of the relevant CSE policies was provided to participants and brief summaries and policy goals were shared, T3, T4 and T7 indicated that 'the language of the policy isn't favourable to help us understand. We don't ever get policies at our school' and 'there's so much sense and what relates to Life Skills that we can use in the policies' (T3, female, Foundation Phase teacher, T4, female, Foundation Phase teacher, T7, female, Foundation Phase teacher), respectively. SA1 observed that 'if the behaviours to be achieved are put into CAPS' and T8 responded that 'not only Life Skills teachers need to know these policies' (T8, female, Foundation Phase teacher). Both SA1 and T8 mentioned that as curriculum managers at district and school level, they could benefit from a better understanding of the policies and would value greater exposure to them. The participants felt that there was a need for them to receive training in policies that influence upon their teaching. They expressed themselves openly by stating:

'We do not learn this when we do training as teachers'. (T3, xxx, $\mathrm{xxx}$ ) and 'I trained as a Life Orientation specialist, but this was never told us'. (T1, female, Foundation Phase teacher)
'Our district subject advisors don't even know this, they should tell us this'. (T6, female, Foundation Phase teacher)

'In the CAPS, it should be clear how policy fits into the curriculum'. (T2, female, Foundation Phase teacher)

'I have been teaching for so long and never ever was given inservice on this'. (SA 2, female, subject advisor - Foundation Phase Life Skills)

Diale (2016) and Francis (2010) agree with teachers regarding the policy context. With the frequent changes to the Life Skills/Life-Orientation policy over the past two decades, many teachers were felt incompetent and anxious to teach the subject. Furthermore, they agree that teachers have received minimal support from departmental officials in teaching practice and pedagogy.

UNESCO (2015a) reports that although it is difficult to measure the impact of national policies and programmes, the declining teen pregnancy rates in South Africa have occurred following the establishment of an enabling policy environment for young people. However, the participants expressed concern about how the policy mandates are translated into practice through implementable school and classroom-based teaching and learning.

\section{Teachers' knowledge and understanding of health goals}

Health goals can direct health policy, guide efforts to improve health and help to evaluate progress (Kirby 2011b). At the start of the discussion on health goals, none of the participants was familiar with what a health goal is or how it is relevant to their teaching. They were shown the BDI model (Figure 1) to explain the health goal and its relevance to Life Skills in the early grades. They were also informed on what study areas are included and which types of behaviour, values and attitudes are targeted in their teaching. T7 commented that the health goals were 'useful to think about them as being achieved over the longer term. Much like outcomes' (T7, female, Foundation Phase teacher). SA1 said that she could see value in the health goals, and that:

' $[I] \mathrm{f}$ they were written into the CAPS Specific Aims they would help teachers to think about why we need learners to learn some of the content was include in Life Skills'. (SA1, female, subject advisor - Foundation Phase Life Skills)

T1, T2, T3, T6 and SA2 interpreted the health goals even further by going directly to the CAPS for their grades and looking for links with the content in the study topics Beginning Knowledge and Personal and Social Well-being.

After working through each health goal with participants and linking their understanding of the health goals with the specific aims and purpose of the study areas Beginning Knowledge and Personal and Social Well-being, participants showed an understanding of the links and association between health goals and types of behaviour. Zulu et al. (2019) agree that individual teachers make decisions on their 
own regarding what and when to teach CSE when left alone. With the appropriate knowledge and understanding of the content, teachers will be guided to teach the age-appropriate content to learners.

Participants T1, T2, T3 and SA1 contributed to a question on the health goals (Figure 2).

The health goals should be clear, measurable targets of what behaviours or outcomes are to be changed (WHO 2010) after the intervention. The BDI model postulates that once a health goal has been identified, then there is a need to determine what factors (protective and risk factors) are relevant and may affect achieving the health goal. A significant observation based on how teachers identified risk and protective factors as determinants of behaviour, as shown in the example below, was that participants more easily identified the risk factors. T8 felt that they were:

' $[M]$ ore aware of what are the risks around us than what will work to address the risk (protective factors). We see what's happening around but we cannot always address the challenges by ourselves'. (T8, female, Foundation Phase teacher)

Participants realised that the achievement of the health goals is dependent on the 'behaviours of individuals like the learners, teachers and parents' (SA1, female, subject advisor-Foundation Phase Life Skills) and 'community cultures and values that are acceptable' (T4, female, Foundation Phase teacher). T6 expressed the opinion that 'if parents don't know better, then parents' attitudes in the home will influence learners' behaviours at an early age already' (T6, female, Foundation Phase teacher). UNESCO (2009) confirms that as the primary socialising agents of children, parents and teachers are a trusted source of information about sexuality for young people.

\section{Teachers' perceptions of behaviour change}

Using Figure 2 (Interpretation of health goals), the participants examined which types of behaviour could be changed later in children's lives by focusing on what they learn in the early grades. Kirby (2011b) postulates that 'road maps specifying the causal pathways between programmes and behaviours' must be clear if behaviour change is to be effected. The value of considering the model when describing an intervention in the Foundation Phase is that the model facilitates later adolescent sexual behaviour being influenced through an early-grade intervention by providing appropriate, relevant knowledge to learners as early as Grades R to 3.

All the teachers agreed that an important reason for teaching CSE in the early grades was its potential to change learners' behaviour. Eight out of the 10 participants agreed that behaviour change in the early grades will most likely influence behaviour later in life. T4 and T7 said, 'if young children are taught properly and without being misguided, they will definitely change their behaviours' (T4, female, Foundation Phase teacher; T7, female, Foundation Phase teacher). In their study in Zambia, Zulu et al. (2019) agree

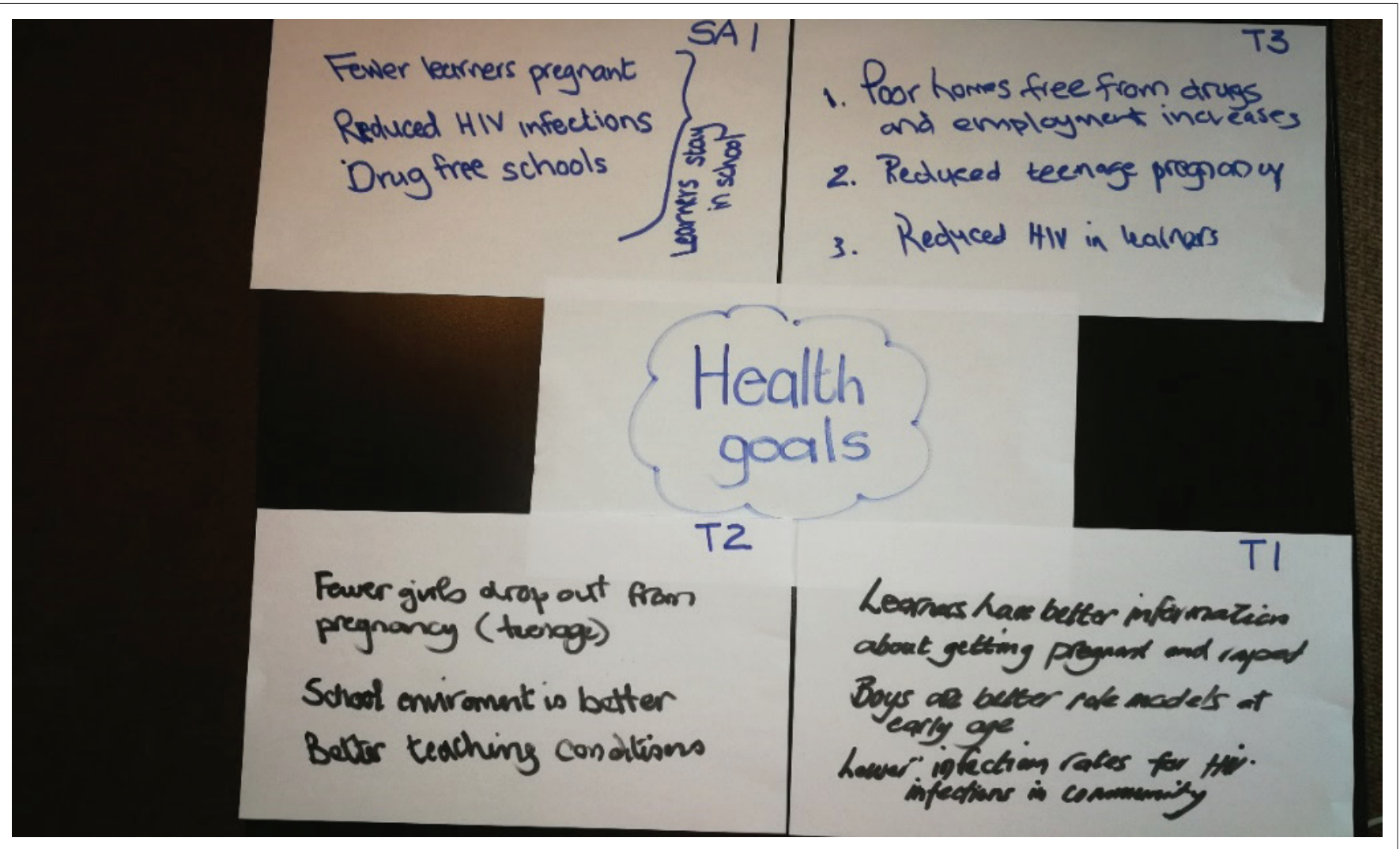

FIGURE 2: Interpretation of the health goals. 


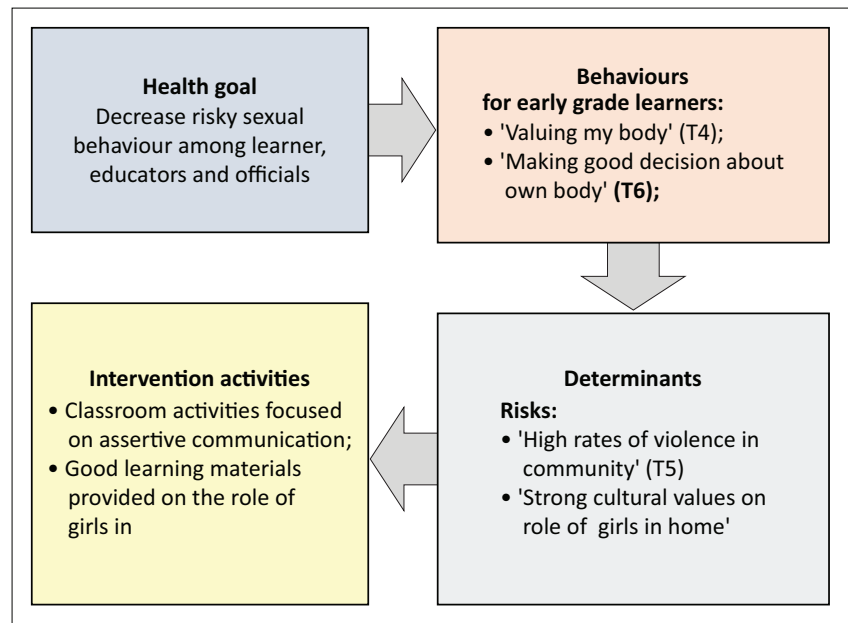

Source: Kirby, D., 2004, BDI Logic Model: A useful tool for designing, strengthening and evaluating programs to reduce adolescent sexual risk-taking, pregnancy, HIV and other STDs, ETR Associates, California. http://recapp.etr.org/recapp/documents/ bdilogicmodel20030924.pdf

FIGURE 3: An example of linking the health goals to interventions by using the Behaviour-Determinant-Intervention model.

that it is critical that teachers do not mislead young learners on CSE education or agree on their own to teach only selected content. This would compromise young learners' knowledge and understanding of the importance of CSE.

Participants used phrases such as 'healthy relationships', 'looking after your own body', 'respecting the bodies of others' (T1, T5 and T7) to link CAPS content with desired changes in behaviour. SA1 felt that 'there were many opportunities in the curriculum, even in the two other subjects (in the Foundation Phase) to address behaviour with the learners' (SA1, female, subject advisor - Foundation Phase Life Skills). All the participating teachers could list at least one type of behaviour that they felt could be associated with the teaching of comprehensive sexuality education.

Participants emphasised the importance of collaboration between Foundation Phase teachers and T3 felt that 'to ensure that learner have integrated learning opportunities, teachers should collaborate' (T3, female, Foundation Phase teacher). Both SA1 and SA2 supported teacher collaboration across grades and agreed that SA could 'support that teachers in the (Foundation) Phase plan together around what behaviour change would be relevant', and that they 'can also help teachers develop integrated learning materials' (SA1, female, subject advisor - Foundation Phase Life Skills; SA2, female, subject advisor - Foundation Phase Life Skills) to promote behaviour change.

\section{Teachers' knowledge of comprehensive sexuality education and links with Life Skills Curriculum and Assessment Policy Statement}

Theme 2 explored teachers' knowledge of CSE and its links with content in the Life Skills CAPS. The Life Skills CAPS do not include a specific study area called CSE. Certain content in the study areas Beginning Knowledge and
Personal and Social Well-being that relate to CSE content has been identified and will provide appropriate links for teaching CSE.

\section{Teachers' knowledge}

When asked what is meant by CSE, all the participating teachers explained what sex education is and how they understand it. Their responses included: 'when to have sex', 'how boys' are bodies different to girls' bodies', 'what is meant by gender' and 'should learners use condoms when they have sex'. T4 mentioned 'the importance of providing a religious link when talking to learners about sex because learners have religious principles that are important in their families' (T4, female, Foundation Phase teacher) and T5 stated that 'sex education is focused on the act of sex and not on the readiness to have a sexual relationship' (T5, female, Foundation Phase teacher).

Teachers felt that learners in the early grades need to be given age-appropriate information. Kirby (2011b) agrees that in the Foundation Phase there are certain topics that must be taught to make learners aware of CSE. Both Francis (2011) and Rooth (2005) agree that many educators across South African schools lack uniformity in professional training and come from a diverse range of fields, which do not always adequately equip them for delivering SE confidently and effectively. This finding collaborates with Zulu et al. (2019) whereby teachers selected content that they were comfortable to teach and omitted other relevant content.

\section{Teachers' perceptions of the links between and gaps in Curriculum and Assessment Policy Statement and comprehensive sexuality education content}

Participants were able to follow the mapping of appropriate CSE content in the ITGSE by looking at the mapping done against the CAPS content (Table 1). Teachers were able to link the ITGSE topics with specific content in different study areas.

Considering the content gaps shown in Table 1, the teachers were able to suggest possible links with the CAPS and SA1 suggested that the links might be stronger 'if linked with the content in other study areas, like Creative Arts' (SA1, female, subject advisor - Foundation Phase Life Skills). Based on the interview content, the researcher was confident that the participating teachers would be able to understand the links and gaps in CAPS and, as observed by T8, could teach the CSE content, 'but would need clear direction on how they would teach that content within CAPS' (T8, female, Foundation Phase teacher). Studies by Francis (2010) and Timmerman (2009) agree that educators' individual experiences, attitudes and personality affect their pedagogical and didactic approach to teaching CSE content. If teachers are empowered and comfortable to teaching sexuality content, then they will be confident in their classrooms. 
According to the BDI model, 'intervention' - a pillar in the model - is necessary as soon as teachers are able to see the link between the gaps in CAPS and the CSE content. The proposed intervention, according to DBE, is to strengthen the Life Skills curriculum content and align it to the ITGSE (UNESCO 2009).

\section{Teacher attitude}

Although the participants' teaching experience in Foundation Phase Life Skills and the number of years they had taught in the classroom varied, they all agreed that the CSE content was necessary. T5 said that even though she had been teaching Life Skills at her school for only a short time, 'I can see how clearly the content fits into the ATP and that makes me feel comfortable to teach it'. T1 felt that even 'my Grade R would be able to do the content. It must just be clearly spelt out and done very practically' (T1, female, Foundation Phase teacher). In support of this finding, Helleve et al. (2009) postulate that numbers of years of teaching HIV, AIDS and sexuality and formal training to teach these subjects associated positively with teachers' confidence'. SA1 and SA2 expressed the opinion that teaching, learning and assessment in the Foundation Phase are highly integrated across the subjects, 'although Life Skills is best suited for including Sexuality Education concepts, there are possibilities to teach (these) in all subjects if teachers integrate' and 'Foundation Phase learners don't learn in silos - they learn in a way that integrates knowledge' (SA1, female, subject advisor - Foundation Phase Life Skills; SA2, female, subject advisor - Foundation Phase Life Skills). T1 mentioned the advantage of 'selecting teaching methods that can be used to teach across all subjects'. (T1, female, Foundation Phase teacher) This is supported by the Department of Education (2002), which lists 'integration' as an important principle of the curriculum, especially in the early grades. Francis (2012:53) agrees that Life Skills is a natural 'home for sexuality education' but confirms that teachers found that the subject content was excessive.

Ahmed et al. (2009) found that teachers expressed conflict between their own personal beliefs and what they were often expected to teach in CSE, but the participants in this study did not raise this as a serious concern. T6 mentioned that she no longer regarded CSE as 'funny content' but realised that it was relevant and 'I am familiar with CAPS, so I can then also teach that content'. T1 stated that she would feel 'challenged if the content was explicit or more sexual because that's not what I'm expecting to teach in comprehensive sexuality education' (T6, female, Foundation Phase teacher).

An important opinion expressed by both SAs was that teachers would feel protected 'if the content is spelt out in policy', since then 'parents cannot confront teachers about content they may not agree to their children being taught'. This was strongly linked to teachers feeling unsure about precisely what content they are expected to teach and the possibility that content may be, as expressed by T7, 'controversial and unacceptable' (T7, female, Foundation Phase teacher). T5 pointed out that it is important for teachers to feel comfortable when teaching new content. Francis (2012) confirms that teachers' confidence will determine how effectively they will teach their learners about sexuality and health.

All the participants felt very confident about their ability to teach the CSE content indicated in the CAPS and T1 and 2 stated 'Sure I can do it as I usually do when teaching the ATP' and 'I could try different teaching approaches with my learners if this is the content' (T1, female, Foundation Phase teacher; T2, female, Foundation Phase teacher), respectively. SIECUS (2004:85) confirms that 'sexuality education is best taught using a variety of teaching methods' and that teachers' 'familiarity with a wide variety of methods for teaching about sexuality can be helpful' for the effective teaching of CSE and building the confidence of teachers.

\section{Factors that limit the inclusion of comprehensive sexuality education}

Dyson (2010) and Brick (1985) propose that although CSE is school based, it complements and augments the SE children receive from their families, religious and community groups, and health professionals. Factors that limit the inclusion of CSE are both internal and external to the school. It is important to note that the issues related to the role and responsibilities of parents were raised by participants as factors that are both internal and external to the school context.

\section{Internal factors limiting the teaching of comprehensive sexuality education}

Vanwesenbeeck et al. (2016:10) posit that 'the school context is thus characterised by many practical and organisational barriers' such as planning, drawing up timetables and the provision of a safe environment, and that 'the school climate is often at odds with what the programme aims to strengthen'. Participants recognised that there would be limiting factors internal to the school that would challenge the inclusion of CSE.

T1, T2, T3 and T7 thought that although it was possible to include the CSE content in Life Skills as well as in other subjects, the participatory teaching methods required might challenge teachers not trained in those methodologies.

$\mathrm{T} 1, \mathrm{~T} 2, \mathrm{~T} 3, \mathrm{~T} 4, \mathrm{~T} 5$ and $\mathrm{T} 6$ agreed with the problems relating to 'time in classroom for teaching', 'giving learning enough time', and 'knowing the right methods to use so we do not affect negatively on what learners need to know when they so young' and emphasised that 'our attitudes need to be positive' (T1, female, Foundation Phase teacher; T2, female, Foundation Phase teacher; T3, female, Foundation Phase teacher; T4, female, Foundation Phase teacher; T5, female, Foundation Phase teacher; T6, female, Foundation Phase teacher). According to UNESCO (2015a:20), 'CSE content 
must respond appropriately to the specific context and needs of learners.

Furthermore, all the participants raised the issues of the provision of resources as a limitation to teaching new content, which is a direct contradiction of the Department of Education's (2001) argument that sexuality education is costeffective and builds on existing resources (teachers and curricula) and requires only low-cost investment on the part of donors and programmes. T8 specifically remarked on how the paucity of resources, such as 'just the usual teaching and learning support materials (LTSM)' (T8, female, Foundation Phase teacher), was a constraint in the classroom, and SA1 saw the lack of resources as a challenge to the support she could offer 'Life Skills teachers who already have to teach everything with nothing' (SA1, female, subject advisor Foundation Phase Life Skills).

Vanwesenbeeck et al. (2016:2) confirm that their research indicated that 'many challenges to the implementation and delivery of CSE in resource poor settings have been identified'. T2 and T4 mentioned very practical considerations, for example, 'to give messages constantly to learners we need to have things like books, games, practical lessons' and 'little posters that learners can see every day' (T2, female, Foundation Phase teacher; T4, female, Foundation Phase teacher) to support the teaching on CSE content.

Class size in the early grades is an important factor that affects the ease with which teachers can use practical teaching approaches. There was a difference in class size across the five schools, with T1 confirming 38 learners in her class and T6 teaching as many as 45 Grade $\mathrm{R}$ learners. Both the SAs confirmed that although the Department was effectively monitoring the application of the norms and standards for a teacher to pupil ratio of 1:40 for primary schools, some schools in certain districts were faced with larger enrolments for Grade R.

The role of the school management teams, of which the Life Skills head of department is a member, has had little or no training in CSE. This was raised by both $\mathrm{T} 7$ and $\mathrm{T} 8$, who are heads of department at their schools, as well as by SA2, who felt that 'if SMTs don't understand the content of Comprehensive Sexuality Education, then it won't happen, no matter how good the teachers are' (SA2, female, subject advisor - Foundation Phase Life Skills). Kirby (2011b) confirms this in his report on school visits and his engagement with school principals when he reports that 'teacher utilisation in Life Skills is raised as a factor limiting effective teaching of CSE in schools'. Both SAs expressed concern about teachers being trained and supported at the school level in a particular year as they teach Life Skills in one grade and are then re-allocated to another subject the following year, despite the support invested in building their capacity and confidence to teach Life Skills. T7 and T8 mentioned that when doing teacher-subject allocations, some school managements often show little regard for the fact that a particular teacher has been trained in Foundation Phase Life Skills. Vanwesenbeeck et al. (2016) confirm this based on research conducted in a number of countries where it was found that despite 'certain criteria for schools to select teachers (e.g. being sex-education experienced, youthfriendly and open-minded regarding sexuality), ... schools often appoint teachers for practical reasons, not taking these criteria into account'.

\section{External factors limit the teaching of comprehensive sexuality education}

Aschool's context is influenced by and reflects the community that the school serves, and the participants mentioned contextual realities that could limit the teaching of CSE. According to the Department of Education, SE should not be confined to the classroom but should become more responsive to how the social environment outside schools profoundly influences sexual behaviour, especially that of girls and marginalised youth. Participants confirmed that the effective functioning of schools is influenced by social, economic and cultural factors within the community, and SA2 felt that 'even the overall learner performance at our schools' (SA2, $x x x, x x x)$ is dependent on the influence and impact of the local environment. This confirms Kirby's (2011b) report that 'in all the communities surrounding the schools, contextual issues were very evident-poverty, lack of jobs and lack of opportunity were very important factors in the environment'.

Participants recognised that the sociocultural and religious values of the community would influence how much a teacher could teach that may not fit into some cultures and traditions'; that 'some things will be taboos in our cultures' and that 'learners are too young to be confused by content that will go against their religious beliefs'. UNESCO (2015a:9) reports that 'CSE content must respond appropriately to the specific context and needs of young people in order to be effective. This adaptability is central to culturally relevant programming and includes understanding the messages that cultures convey around gender, sex and sexuality'.

Participants saw parental attitudes and misconceptions as limiting the effective teaching of SE content. In response to the question about who is part of the school community, all the participants referred to the role of parents and the support they give to the school. Amongst the problems experienced with parents was their reluctance to discuss risky behaviour by their children. Participants mentioned concerns such as 'parent's denial', 'taboos to talk with children' and 'it's a parent's role to talk to their children' about SE. UNESCO (2015a:19) posits that 'parents can play an important role in communicating with their children about sexuality, relationships and well-being, particularly amongst younger age groups'. T7 and SA2 were of the opinion that the appropriate information for which the child is ready needs to be considered when parents themselves give information. SA1 felt that 'parents should participate more at school level with the teacher and get what is appropriate for their 
children' (SA1, female, subject advisor - Foundation Phase Life Skills).

T7 mentioned that there were 'no local services and clinics' to support learner referrals, which might assist teachers' efforts to encourage learners to talk about their health challenges. T2 felt that she 'would not want to send her learners home' with messages related to SE 'if the home was going to reject the messages because they do not support this kind of content being taught'. UNESCO (2018) emphasises the need for effective SE to be combined with accessible services and welltrained providers who have high quality, unbiased knowledge of family-planning commodities in particular.

\section{Recommendations and conclusion}

With reference to the study's research findings, the following recommendations can be made for how to strengthen the incorporation of CSE in the curriculum in the early grades.

\section{Recommendations for building teacher knowledge}

The BDI model allows the policy context to be seen as relevant and as an influencing practice in the classrooms by linking policy goals with teaching plans and programmes in the classroom. The logic of the BDI model facilitates an educational response, which includes the teaching and learning of appropriate content, to the health goals set in health-promoting policies towards creating safe, healthy learning environments in schools.

Health goals and the targeted behaviour change that will have an impact on healthy sexual and reproductive choices in learners later in their lives can be an important inclusion in an early-grade intervention promoting CSE within the Foundation Phase curriculum. Through finding conceptual links between grade-specific content within Life Skills CAPS and the concepts detailed for effective SE programmes in the ITGSE, teachers are provided with a clear indication of what knowledge is to be taught and what teachers themselves need to know to teach effectively. Addressing the gaps that exist in the CAPS provides additional understanding on content that needs to be included in the Life Skills curriculum in the early grades.

Core messaging about healthy sexual and reproductive choices and lifestyle is an important feature of a SE programme as well as advocating policy goals and guiding learning activities to promote a focus on CSE within earlygrade teaching and learning.

\section{Recommendations for inclusion of comprehensive sexuality education content into life skills Curriculum and Assessment Policy Statement}

In the Foundations Phase, the emphasis is on building a positive self-image like caring for oneself physically and emotionally, building self-confidence and self-esteem and giving opportunities to make decisions confidently about a range of issues (DBE 2011). With the inclusion of CSE content into the Life Skills CAPS in the early grades, there is a greater chance of improving the knowledge of learners about healthy sexual development, changing their attitudes and choices about their own sexual and reproductive lives in their later lives and for impacting their sexual behaviours when they are ready for sexual relationships.

The selection of content that is to be included into the Life Skills CAPS should be linked directly with the health goals and targeted behaviours so that the relevance of the activities presented in the ATP is seen by both learners and teachers as contributing towards behaviour change and building selfefficacy.

Curriculum and Assessment Policy Statement focuses on developing the learners holistically, and the subject knowledge domains are spelt out in such a way that subject knowledge can be integrated. Comprehensive Sexuality Education content, although mapped into Life Skills, should be taught in an integrated fashion across subjects from Grade $\mathrm{R}$ to 3 . Learning activities can be developed and included within the ATP to show conceptual progression of new concepts so that learning remains age-appropriate.

To facilitate teaching and to build the confidence of teachers to teach what may be perceived as difficult content to teach, scripted lesson plans (SLPs) can be developed and provided to teachers in the Foundation Phase. Scripting what teachers must teach ensures that content is aligned to CAPS, that assessment tasks are relevant and focused on measuring learner performance and that teachers have the relevant resources to teach the CSE content. Scripting for learners allows for appropriate learning styles for the SE content to be selected; learning activities can model the like of peer learning promoted for talking about behaviour change and could include materials that learners could share within their home environments. Implicitly, parental knowledge and support can be developed to support teaching and learning in the classroom.

\section{Recommendations for teacher development and training}

Initial teacher training (IPTD) curricula at Higher Education Institutes would need to include new CSE content into their initial teacher-training programmes. Given that Life Skills in the early grades and Life Orientation in Grades 4-12 are compulsory subjects, teacher-training course modules would need to include CSE as a mandatory module and include appropriate assessment practices, participatory teaching methodologies and skills for developing classroom-based resource materials.

The inclusion of the policy context is important for teachers and provides national mandates and guidelines as well as the implementation plans for schools to adhere. Teachers will benefit from understanding how policy is translated into 
practice in the classroom and how policy then affects in a real way learner performance.

Continued professional teacher development offers an opportunity to upgrade teacher content knowledge and skills to support teaching CSE within the Life Skills CAPS.

Training programmes, either short in-service training or initial professional teacher development programmes offered as part a teacher qualification need to include a component of building teachers' values and attitudes to teaching SE constructs within the curriculum.

\section{Recommendations for teacher content knowledge upgrade}

Teacher development interventions, be it in-service support training conducted at district and school level or formal upgrade training programme accessed by teachers through a part qualification at an HEI, course would need to shift teachers from what they know and can teach to what the curriculum content will need to be taught effectively.

Currently departmental content upgrade courses are standardised programmes decided on by the needs of the curriculum. The curriculum's needs do not necessarily match the needs of the teachers' own knowledge. Measuring what that shift needs to be can be established only by a pre-test assessment of teacher content knowledge. The pre-test will establish what programme and what 'dosage' of training the teacher needs. Especially in the context of building positive values and attitudes, teacher-training course modules will need a specific focus on providing teachers with tools that promote self-reflection and praxis for building values and attitudes.

Ongoing research-based, content-based training with the aim of promoting an inclusive approach to teaching CSE is required so that curriculum policymakers and materials developers will provide support for teaching content.

There is a further recommendation that the current district engagement with teachers would benefit from training teachers in and on their own school context and on the social context prevalent in that district.

\section{Recommendations for support for implementing a Comprehensive Sexuality Education programme}

The following recommendations are made based on the nature of support identified to support the incorporation of CSE with the Life Skills CAPS in the early grades:

- Psychosocial support for teachers and learners can be strengthened by strengthening the relationships and process of consultation with the district-based support teams.

- School Management has a crucial role in advocating for and managing the process of engaging with parents on the nature and scope of the CSE programme within the
Life Skills CAPS. Formal engagement sessions and continuous communication with parents will support the implementation of CSE in the classroom.

- District support plans for curriculum implementation will monitor and suggest what support is needed at the level of the teacher and classroom. Evidence from the monitoring process will provide data on how teaching and learning can be strengthened.

- District support plans will be specific to the school context and teaching and learning needs, which allows for a break away from the 'one-size-fits-all' approach to supporting curriculum implementation at school level.

- A strong advocacy campaign for parents providing the rationale for and nature of CSE content is to be included in the strategy for including CSE in the early-grade CAPS.

In conclusion, if CSE is to be successfully implemented in schools, the researcher proposes that the Department of Education gives the above recommendations serious consideration. Empowered with knowledge and an understanding of the content of CSE, young children will be taught the skills required to become acutely aware of their environment, make appropriate decisions, become aware of sexual abuse and communicate effectively when they experience abuse.

\section{Acknowledgements}

We acknowledge the University of Pretoria for supporting this study and all critical readers who assisted in commenting on this study.

\section{Competing interests}

The authors have declared that no competing interests exist.

\section{Authors' contributions}

All authors contributed equally to this work.

\section{Ethical consideration}

Approval to conduct this study was received from the University of Pretoria, ethical clearance number EC 17/11/01, 01 August 2019.

\section{Funding information}

The research received no specific grant from any funding agency in the public, commercial or non-profit sectors.

\section{Data availability statement}

Data sharing is not applicable to this article as no new data were created or analysed in this study.

\section{Disclaimer}

The views and opinions expressed in this article are those of the authors and do not necessarily reflect the official policy or position of any affiliated agency of the authors. 


\section{References}

Ahmed, N., Flisher, A., Mathews, C., Jansen, S. \& Mukoma, W., 2009, 'HIV education in South African schools: The dilemma and conflicts of educators', Scandinavian Journal of Public Health 37(2), 48-54. https://doi.org/10.1177/1403494808097190

Artz, L., Ward, C.L., Leoschut, L., Kassanjee, R. \& Burton, P., 2018, 'The prevalence of child sexual abuse in South Africa: The optimus study South Africa', South African Medical Journal 108(10), 791-792. https://doi.org/10.7196/SAMJ.2018. v108i10.13533

Ashcraft, A.M. \& Murray, P.J., 2017, 'Talking to parents about adolescent sexuality', National Centre for Biotechnology Information 64(2), 305-320. https://doi. org/10.1016/j.pcl.2016.11.002

Beyers, C., 2013, 'Sexuality educators: Taking a stand by participating in research', South African Journal of Education 33(4), 1-14. https://doi.org/10.15700/201412171342

Berglas, N.F., Constantine, N.A. \& Ozer, E.J., 2014, 'A rights-based approach to sexuality education: Conceptualization, clarification and challenges, Perspectives on Sexual and Reproductive Health 46(2), 63-72. https://doi.org/10.1363/46e1114

Bloor, M., Frankland, F., Thomas, M. \& Robson, K., 2002, Focus group in social research, Sage, London.

Boyatzis, R.E., 1998, Transforming qualitative information: Thematic analysis and code development, Sage, Thousand Oaks, CA.

Berglas, N.F., Constantine, N.A. \& Ozer, E.J., 2014, 'A Rights-Based Approach to Sexuality Education: Conceptualization, Clarification and Challenges', Perspectives on Sexual and Reproductive Health 46(2), 63-72. https://doi.org/10.1363/46e1114

Breuner, C.C. \& Mattson, G., 2016, 'Sexuality education for children and adolescent', Journal of the American Academy of Paediatrics 132(2), e20161348. https://doi. org/10.1542/peds.2016-1348

Brick, P., 1985, 'Sexuality education in elementary school', SIECUS Report 13(3), 1-4.

Creswell, J.W., 2009, Research design: A qualitative, quantitative, and mixed method approaches, Sage, Newbury Park, CA.

Denzin, N.K. \& Lincoln, Y.S. (eds.), 2011, The Sage handbook of qualitative research, 4th edn., Sage, London.

Department of Education (DBE), 2002, The revised national curriculum statement Grades $R$ to 9 (schools) overview, Government Printers, Pretoria.

Department of Basic Education (DBE), 2011a, Curriculum and assessment policy statement: Life skills foundation phase, Government Printers, Pretoria.

Department of Basic Education (DBE), 2011b, Integrated strategic planning framework for teacher education and development in South Africa 2011-2025, Government Printers, Pretoria.

Department of Basic Education (DBE), 2011c, Curriculum and Assessment Policy Statement: Life Skills Foundation Phase (CAPS), Government Printers, Pretoria.

Department of Basic Education (DBE), 2017, DBE national policy on HIV, STIs and for learners, educators, school support staff and officials, Government Printers, Pretoria.

Department of Education, 2001, Protecting the right to innocence. The impact of Sexuality Education, Government Printers, Pretoria.

Department of Education, 2002, Revised national curriculum: Overview, Government Printers, Pretoria.

Diale, B.M., 2016, 'Life orientation educators' career development needs in Gauteng: Are we missing the boat?', South African Journal of Higher Education 30(3), 85-110. https://doi.org/10.20853/30-3-670

Dyson, S., 2010, Parents and sex education. Parent's attitude to sexual health education in WA schools, Department of Public Health, Western Australia.

Francis, D., 2010, 'Sexuality education in South Africa: Three essential questions, International Journal of Educational Development 30(3), 314-319.

Francis, D.A., 2011, 'Sexuality education in South Africa: Wedged within a triad of contradictory values', Journal of Psychology in Africa 21(2), 317-322. https://doi. org/10.1080/14330237.2011.10820463

Francis, D.A., 2012, 'Teacher narratives on the teaching of sexuality and HIV/AIDS education', Comunitas 17, 45-59.

George, G., Tucker, L.A., Panday, S. \& Khumalo, F., 2019, ‘Delivering sexuality education: A review of teaching pedagogies within South African schools', Perspectives in Education 37(1), 101-114. https://doi.org/10.18820/2519593X/pie.v37i1.8

Guder, S.Y. \& Alabay, E., 2018, 'Children's questions and answers of parents: Sexual education dilemma', International Journal of Progressive Education 14(6), 138-151. https://doi.org/10.29329/ijpe.2018.179.11

Guest, G., MacQueen, K.M. \& Namey, E.E., 2012, Applied thematic analysis, Sage, Los Angeles, CA. https://doi.org/10.4135/9781483384436

Helleve, A., Flisher, A.J., Onya, H., Kaaya, S., Mukoma, W., Swai, C. et al., 2009 'Teachers' confidence in teaching HIV/AIDS and sexuality in South African and Tanzanian schools', Scandinavian Journal of Public Health 37(2), 55-64. https:// doi.org/10.1177/1403494808095085
Kirby, D., 2004, BDI Logic Model: A useful tool for designing, strengthening and evaluating programs to reduce adolescent sexual risk-taking, pregnancy, HIV and evaluating programs to reduce adolescent sexual risk-taking, pregnancy, HIV and
other STDS, ETR Associates, California. http://recapp.etr.org/recapp/documents/ other STDS, ETR Associates,
bdilogicmodel20030924.pdf.

Kirby, D., 2011a, A way forward: Recommendations to the South African DBE to design and implement effective HIV Education Curriculum that reduces Sexual Risk for HIV Department of Basic Education, Government Printers, Pretoria.

Kirby, D., 2011b, Sex education: Access and impact on sexual behaviour of young people, United Nations Expert Group Meeting on Adolescents, Youth and Development, Department of Economic and Social Affairs, United Nations Secretariat, New York, NY.

Kurtuncu, M., Akhan, K.U., Tani, I.M. \& Yildiz, H., 2015, 'The sexual development and education of preschool children: Knowledge and opinions from doctors and nurses', Sex Disability 33(2), 207-221. https://doi.org/10.1007/s11195-015-9393-9

Mathews, B. \& Collin-Vezina, D., 2019, 'Child sexual abuse: Toward a conceptual model and definition', Trauma, Violence and Abuse 20(2), 131-148. https://doi. org/10.1177/1524838017738726

Mncube, V. \& Dube, B., 2019, 'Reconceptualising teacher professionalism to address school violence: A quest to end corporal punishment', The Independent Journal of Teaching and Learning 14(1), 86-101.

Ott, M.A. \& Santelli, J.S., 2007, 'Abstinence and abstinence-only education', Current Opinion Obstetrics and Gynecology 19(5), 446-452. https://doi.org/10.1097/ GCO.0b013e3282efdc0b Pijoos, L., 2017, 'Sexual assault claims at primary school: Lesufi slams', News 24,
viewed 23 November 2017, from https://www.news24.com/SouthAfrica/News/ sexual-assault-claims-at-primary-school-lesufi-slams-principal-20171123.

Robinson, K.H. \& Davies, C., 2017, 'Sexuality education in early childhood', in L. Allen \& M. Rasmussen (eds.), The Palgrave handbook of sexuality education, pp. 217-242, Palgrave Macmillan, London.

Rooth, E., 2005, 'An investigation of the status and practice of life orientation in South African schools in two provinces', Doctoral dissertation, University of the Western Cape, Cape Town.

SIECUS, 2004, Culturally competent sexuality education: Educating and empowering communities, Sex Information and Education Council of the U.S., New York, NY.

Timmerman, G. \& Timmerman, M.C., 2009, 'Teaching skills and personal characteristics of sex education teachers', Teaching and Teacher Education 25(3), 500-506. of sex education teachers', Teaching and
https://doi.org/10.1016/j.tate.2008.08.008

UNESCO, 2009, International technical guidance on sexuality education - An evidenceinformed approach for schools, teachers and health educators, United Nations Educational, Scientific and Cultural Organization, Paris.

UNESCO, 2015a, Comprehensive sexuality education in teacher training in Eastern and Southern Africa, United Nations Educational, Scientific and Cultural Organization, Paris.

UNESCO, 2015b, Emerging evidence, lessons and practice in comprehensive sexuality education. A global review, United Nations Educational, Scientific and Cultura Organization, Paris.

UNESCO, 2018, International technical guidelines on sexuality education. An evidence-informed approach, United Nations Educational, Scientific and Cultural Organization, Paris.

United Nations Population Fund (UNFPA), 2015, Incorporating comprehensive sexuality education within basic and higher institutions of learning in KwaZuluNatal, viewed August 2017, from http://www.unfpa.org/comprehensivesexuality-education.

Vanwesenbeeck, I., Westeneng, J., De Boer, T., Reinders, J. \& Van Zorge, R., 2016 'Lessons learned from a decade implementing comprehensive sexuality education in resource-poor settings: The World Starts With Me', Sex Education 16(5), 471in resource-poor settings: The World Starts With Me,
486. https://doi.org/10.1080/14681811.2015.1111203

Venketsamy, T., 2018, 'Challenges experienced by Black teachers teaching Comprehensive Sexuality Education in schools', Journal of Educational Studies 17(1), 20-42.

Walker, J. \& Milton, J., 2006, 'Teachers' and parents' roles in the sexuality education of primary school children: A comparison of experiences in Leeds, UK and in Sydney, Australia', Sex Education 6(4), 415-428. https://doi. org/10.1080/14681810600982267

Weaver, H., Smith, G. \& Kippax, S., 2005, 'School-based sex education policies and indicators of sexual health among young people. A comparison of the Netherlands, France, Australia and the United States', Sex Education 5(2), 171-188. https://doi. org/10.1080/14681810500038889

World Health Organization (WHO), 2010, Regional office for Europe and BZgA, Standards for sexuality education in Europe: A framework for policy makers, education and health authorities and specialists, BZgA, Köln.

Yin, R.K., 2018, Case study research and applications: Design and methods, 6th edn., Sage, Los Angeles, CA.

Zulu, J.M., Blystad, A., Haaland, M.E.S., Michelo, C., Haukanes, H. \& Moland, K.M., 2019, 'Why teach sexuality education in school? Teacher discretion in implementing comprehensive sexuality education in rural Zambia', Internationa Journal of Equity Health 18, 116. https://doi.org/10.1186/s12939-019-1023-1 